\title{
Epidemiological study on gastrointestinal tract hel- minthosis of small ruminants in Dawuro Zone
}

\author{
Amenu Asha*1, Bulako Chebo ${ }^{1}$ \\ ${ }^{1}$ School of Veterinary Medicine, Wolaita Sodo University, Wolaita Sodo, Ethiopia. \\ *Corresponding author: E-mail address: amenuasha@gmail.com
}

\section{Abstract}

An epidemiological study on GIT helminthosis of small ruminants in three different agro ecological zones (AEZ) of Dawuro Zone was carried out from March to August 2012 on 21 gastrointestinal tracts and 486 faecal samples collected from sheep and goats to identify helminth species, determine the occurrence and factors related to the helminth infection. The cross sectional study was carried out through postmortem examination (PME) and coprological examinations using sedimentation, floatation and McMaster egg counting methods. PME revealed the existence of nematode, cestode and trematode species in $95.2 \%, 33.3 \%$ and $4.8 \%$ of animals, respectively. The postmortem examination also indicated the existence of ten (10) nematode species with different percent prevalence (Haemonchus contortus, 85.7; Trichostrongylus colubriformis, 76.2; Oesophagostomum columbianum, 52.4; Trichuris ovis, 42.9; Trichostrongylus axei, 19.0; Bunostomum trigonocephalum, 14.3; Teladorsagia spp., 14.3; Trichostrongylus falculatus, 9.5; Trichostrongylus longyspicularis, 4.8 and Cooperia curticei, 4.8). The variation in the prevalence of individual nematode species on agro-ecological basis was significant $(\mathrm{P}<0.05)$ except for Bunostomum trigonocephalum ( $p>0.05$ ). Except for T. axei, the seasonal prevalence of all nematodes was significantly varied $(p<0.05)$ between seasons of the year. Mean nematode burden have shown significant differences for seasonal variation $(p<0.05)$. The variation was also observed between body condition differences $(p<0.05)$, and age differences especially for $H$. contortus $(p<0.05)$. Out of $95.2 \%$ of nematode infected animals in the study area, $70 \%$ harbored moderate level infestation and, 30\% were lightly infected by GIT nematode species. Faecal examination results from population of sheep and goats during two sampling periods indicated significant seasonal variation $(p<0.05)$ in prevalence and mean fecal egg counts for all study sites. Majority (54\%) of infected animals had a faecal egg count in the range of 50-800 and only few proportions $(10.4 \%)$ of animals had faecal egg count over 1200 during wet season of the year. The widespread existence of various helminthes in the form of polyparasitism in sheep and goats in all agroecology of the study area, both at postmortem and coproscopic examination suggest the institution of various control measures including strategic anthelmintic treat- 
ment for efficient utilization of the small ruminant resources at hand.

Keywords: Coproscopy, Dawuro Zone, Epidemiology; GIT helminthes; Postmortem; Small ruminant

http://dx.doi.org/10.4314/evj.v19i1.9

\section{Introduction}

In Ethiopia, sheep and goats account on an average for $40 \%$ of cash income and $19 \%$ of the total value subsistence found derived from all livestock production. They contribute a quarter of the domestic meat consumption; about $40 \%$ fresh skins and $92 \%$ of the value of semi processed skin and hide export trade. Ethiopia can export 700,000 sheep and 2 million goats annually, and at the same time supply 1,078,000 sheep and 1,128,000 goats for the domestic market. The current annual off take rate of sheep and goats is, however, only $33 \%$ and $35 \%$ respectively. The average carcass weight of Ethiopian sheep and goats is 10kg; which is the second lowest in sub-Saharan Africa Adane Hirpa and Girma Abebe (2008)

Complementary feeding habit of sheep and goats, their small size, early maturity, short reproductive cycle, high incidence of multiple births, their ability to restore the flock size more rapidly and their survival during the adverse environmental conditions such as drought makes these animals preferable to be raised by wide range of society including children, women, poor farmers and up to wide scale level (Devendra and Mcleory, 1982; Gatenby, 1991; Mike, 1996; Adane Hirpa and Girma Abebe (2008)).

However the full exploitation of this huge resource is hindered due to various factors such as drought, poor genetic potential of the animals, traditional system of husbandry and the presence of different livestock diseases (Ibrahim, 1998). Among the factors that account for the lowest performance of these resources are various diseases of sheep and goats; of which helminth parasites play great role by causing huge economic loss through morbidity and mortality (Over et al., 1992). The causes of helminth parasitism in ruminant livestock are multiple and often interactive, the vast majority of cases are due to any of the following basic reasons: an increase in the number of infective stages on pasture, an alteration in host susceptibility, the introduction of susceptible stock in to an infected environment and the introduction of infections in to an environment (Urquhart et al., 1996). 
Studies conducted in various corners of the country indicated high prevalence of Gastrointestinal tract helminthosis in all agroecological zones and causing serious loss of production and productivity of small ruminants (Achenef Melaku, 1997; Desalegn Lidetu, 1999; Esayas Gelaye, 1999; Abebe Wosene and Esayas Gelaye, 2001; Etana Debella, 2002; Haileleul Nigussie, 2002; Amenu Asha and Abebe Wosene, 2007; Sisay Menkir, 2007).

Despite large number of sheep and goats' population and conducive environment for sheep and goat raising, Dawuro zone has not been assessed for the helminthosis problem. Therefore this study has been conducted to determine the prevalence and burden of helminth infection and to identify the involved helminth species.

\section{Materials and Methods}

\section{Study area}

The study areas are Loma and Tocha weredas of Dawuro Zone. The Zone is located at $512 \mathrm{~km}$ South West of Addis Ababa. Dawuro zone lies between 6.59$7.34^{\circ} \mathrm{N}$ and $36.68-37.52^{\circ} \mathrm{E}$. Altitude of the zone is $501-3000$ meter above sea level with mean monthly temperature ranges from $15.1^{0}-27.5^{\circ}{ }_{\mathrm{c}}$ and annual rainfall of $1201-1800 \mathrm{~mm}$. The Zone is comprised of $21 \%$ high land, $41.0 \%$ midland and $38 \%$ low land agro ecologies. The Zone receives a bimodal rainfall in short (February to March) and long (May to September) rainy seasons. Dawuro zone practice a crop - livestock mixed farming and keep combination of livestock species integrated with a wide range of cereals, pulses, root and tuber and cash crops. In Dawuro zone larger portion of land was allocated for crop cultivation and only $18 \%$ of the total land were allocated for livestock grazing (Tsedeke Kocho and Endrias Geta, 2011).

\section{Study animals}

The study animals are indigenous breeds of sheep and goats raised in the highland areas of Tocha and highland, midland and lowland areas of the Loma wereda. The estimated figures of sheep and goat population are indicated on the table below. 
Table1: sheep and goat population of study weredas

\begin{tabular}{lcc}
\hline Livestock class & Loma wereda & Tocha wereda \\
\hline Sheep & 20,126 & 59,249 \\
Goat & 22,442 & 15,077 \\
\hline
\end{tabular}

Source: (Dawuro Zone Agricultural Bureau, 2012)

\section{Study methodology}

\section{Study type}

Cross sectional study for prevalence determination by postmortem and faecal examination and prospective longitudinal study for studying the seasonal dynamics of helminthes (Hansen and Perry, 1994; Toma et al., 1996) were used.

\section{Sampling method and sample size determination}

Systematic random sampling method was used to collect fecal samples and purposive sampling method was used to obtain animals for postmortem examination. The sample size was determined based on the formula in Thrusfield (1995), considering $98.6 \%$ helminth expected prevalence in postmortem examination and $80 \%$ helminth expected prevalence in coprology from the neighboring zones(Wolaita and Gamo Gofa) at 95\% confidence interval and 5\% desired absolute precision as described in Thrusfield (1995).

\section{Study procedures}

\section{A. Post mortem examination method}

Sheep and goats bought from the study areas (High land, Midland and lowland) were brought to Wolaita Sodo town. A day before slaughtering, antemortem examination was performed and for each animal its village of origin, age, sex, body condition and its general health condition were properly recorded.

Following slaughter the gastrointestinal tract was removed, the rumen was inspected for fluke (Paramphistomum) and the abomasum, small intestine and large intestine were immediately isolated by three ligatures (between omasum and abomasum, abomasum and small intestine, ileum and caecum) to avoid mixing of the contents.

Collection of the contents of rumen, abomasum and intestines, and recovery of helminth species was made according to, MAFF, 1977 and Urquhart et al., 1996. Identification and counting procedures was done according to MAFF, 
1977; Soulsby, 1982; Hansen and Perry, 1994; Kaufmann, 1996 and Urquhart et al., 1996.

In a mixed infection by nematode species, the intensity of nematode count was classified as low $(<2000$ nematode), moderate $(2000-10,000)$ and high $(>10,000)$ as described in Radostits et al., 2000.

\section{B. Coprological method}

Faecal samples obtained from rectum of sheep and goats, at field (population) and from slaughtered animals were subjected to qualitative (flotation and sedimentation), and quantitative (modified McMaster) techniques. Faecal egg count was performed using modified McMaster technique; each nematode egg counted represents 50 eggs per gram of faeces (Hansen and Perry, 1994; Hendrix, 1998).

Classification of the intensity of nematode infection was made based on faecal egg counts as light (50-800 epg), moderate (801-1200 epg) and heavy infections (>1200 epg) as described in Hansen and Perry, 1994 for the mixed infections in grazing small ruminants.

\section{Statistical analysis methods}

The data collected was recorded in Microsoft excel. The independent variables analysed were: agro-ecological zones (highland, midland and lowland), species of animals (Goat and sheep), sex of animals (male and female), age of animals (less than 1 year, 1-2 years, more than 2 years) and season of the year (dry and wet). The dependant variables analysed were faecal egg counts and nematode counts. Because of the skewness in their distribution, faecal egg counts and nematode counts were subjected to a logarithmic transformation $[\log (x+1)]$ for analysis.

To compare the difference between means and proportions SPSS 16.0 software was used for univariate analysis of variance (ANOVA) to compare more than two means, t-test to compare the difference between two means, and chisquare to compare the difference between the proportions for faecal egg count (epg) and post mortem (nematode burden) results. 


\section{Results}

\section{Post mortem results}

\section{Helminth species identification and their prevalence}

The study carried out on GIT helminthes of sheep and goats, from March to August 2012 (representing dry and wet seasons of the year) in two Weredas of Dawuro zone (Loma and Tocha) has revealed three helminth classes with different levels of prevalence:95.2, 33.3 and 4.8 percent prevalence of nematode, cestode and trematode classes, respectively(Fig.1). The overall prevalence of helminth infection from postmortem examination of 21 sheep and goats was $100 \%$. The prevalence of nematodes, cestodes and trematodes was significantly higher during the wet season than the dry season of the year in the study site $(\mathrm{p}<0.05)$.

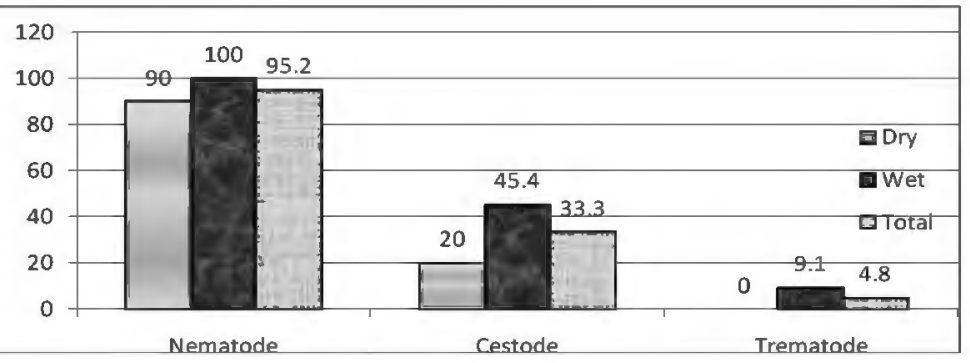

Figure 1. Seasonal Prevalence (\%) of GIT helminthes of sheep and goats at study sites.

The total helminth prevalence doesn't vary on agro-ecology, but individual helminth classes have variation on agro-ecology (Tab. 2). The results indicate that there was highest nematode prevalence than the other two classes of helminthes (trematodes and cestodes). Only one case (4.8\%) of Paramphistomum spp. (rumen fluke) was detected by postmortem examination and $33.3 \%$ of postmortem examined animals were found to harbor two species of cestodes (Moniezia expansa and Thysaniezia spp.) as indicated on Table 2. 
Table 2: Prevalence of GIT helminth class by Agro-ecology.

\begin{tabular}{lcccc}
\hline Helminth class & $\begin{array}{c}\text { HL (N=6) } \\
\%+\mathbf{~}\end{array}$ & $\begin{array}{c}\text { ML(N=8) } \\
\%+\mathbf{v e}\end{array}$ & $\begin{array}{c}\text { LL(N=7) } \\
\%+\mathbf{e}\end{array}$ & $\begin{array}{c}\text { Total (N=21) } \\
\text { \%+ve }\end{array}$ \\
\hline Nematodes & 100 & 87.5 & 100 & 95.2 \\
Trematodes & - & 12.5 & - & 4.8 \\
Cestodes & 33.3 & 25.0 & 42.9 & 33.3 \\
Over all Helminths & 100 & 100 & 100 & 100 \\
HL: High land, ML: Mid land, LL: Low land & & &
\end{tabular}

The overall prevalence of nematodes in the study site was $95.2 \%$ and there were 10 nematode species identified at different prevalence rates. The study revealed that the highest prevalence was for the most pathogenic blood sucking parasite, $H$. contortus (85.7\%), followed by $T$. colubriformis $(76.2 \%)$ and $O$. columbianum $(52.4 \%)$ as indicated on table 3 below.

Table 3: Prevalence of ten nematode species in the study site during the study period.

\begin{tabular}{lc}
\hline Nematode species & Prevalence (\%) \\
\hline Trichostrongylus axei & 19.0 \\
T. colubriformis & 76.2 \\
T. falculatus & 9.5 \\
T. longispicularis & 4.8 \\
Haemonchus contortus & 85.7 \\
Teladorsagia spp. & 14.3 \\
Oesophagostomum columbianum & 52.4 \\
Bunostomum trigonocephalum & 14.3 \\
Trichuris ovis & 42.9 \\
Cuperia curticei & 4.8 \\
Over all & 95.2 \\
\hline
\end{tabular}

The prevalence of different nematode species varies on agro-ecological Zone difference. The pathogenic nematode species, $H$. contortus and Oesophagostomum columbianum were found to exist at higher prevalence in lowland area than the other two agroecologies. Others such as Teladorsagia spp. and Cooperia curticei were limited to mid and high lands, respectively. The prevalence of Bunostonum trigonocephalum and Trichuris ovis were found to be similar in all agroecological zones (Table 4). 
Table 4: Prevalence of nematode species in Agro-ecological zones of study site during study period.

\begin{tabular}{lccc}
\hline Nematode species & Highland (N=6) & $\begin{array}{c}\text { Midland } \\
(\mathbf{N = 8})\end{array}$ & Lowland (N=7) \\
\cline { 2 - 4 } & $\%+\mathbf{v e}$ & $\%+\mathbf{v e}$ & $\%+\mathbf{e}$ \\
\hline Trichostrongylus axei & - & 25.0 & 28.6 \\
T. colubriformis & 100.0 & 50.0 & 85.7 \\
T. falculatus & - & - & 28.6 \\
T. longispicularis & - & 12.5 & - \\
Haemonchus contrtus & 83.3 & 75.0 & 100.0 \\
Teladorsagia spp & - & 37.5 & - \\
Oesophagostomum columbianum & 16.7 & 50.0 & 85.7 \\
Bunostonum trigonoceplalum & 16.7 & 12.5 & 14.3 \\
Trichuris ovis & 33.3 & 50.0 & 42.9 \\
Cooperia curticei & 16.7 & - & - \\
\hline
\end{tabular}

Post mortem examination of 21 sheep and goats during dry and wet seasons of the year at two woredas of Dawuro zone, revealed significant seasonal variation on the prevalence of T. colubriformis, Haemonchus contortus, Oesophagostomum columbianum and Bunostomum trigonocephalum. The prevalence of the above parasite species was significantly higher during wet season of the year than the dry season, while the prevalence of Trichuris ovis was significantly higher during dry season of the year as indicated on table 5 below.

Table 5: Seasonal prevalence of Nematode species of small ruminants at study site.

\begin{tabular}{lccccc}
\hline \multirow{2}{*}{ Nematode species } & \multicolumn{2}{c}{ Season } & & & \\
\cline { 2 - 4 } & Dry $(\mathbf{N}=\mathbf{1 0})$ & Wet(N=11) & Total & $\mathbf{X}^{\mathbf{2}}$ & P-value \\
\hline Trichostrongylus axei & 20.0 & 18.2 & 19.0 & 0.5 & 0.5 \\
T. colubriformis & 60.0 & 90.9 & 76.2 & 6.5 & 0.003 \\
T. falculatus & 20.0 & - & 9.5 & & \\
T. longispicularis & 10.0 & - & 4.8 & & \\
Haemonchus contortus & 70.0 & 100.0 & 85.7 & 6.62 & 0.003 \\
Teladorsagia spp. & 10.0 & 18.2 & 14.3 & 15.2 & 0.008 \\
Oesophagostomum columbianum & 40.0 & 63.6 & 52.4 & 10.6 & 0.043 \\
Bunostomum trigonocephalum & 10.0 & 18.2 & 14.3 & 15.2 & 0.008
\end{tabular}




\begin{tabular}{lccccc}
\hline Nematode species & \multicolumn{2}{c}{ Season } & & \\
\cline { 2 - 4 } & Dry $(\mathbf{N}=\mathbf{1 0})$ & $\mathbf{W e t}(\mathbf{N}=\mathbf{1 1})$ & Total & $\mathbf{X}^{2}$ & P-value \\
\hline Trichuris ovis & 70.0 & 18.2 & 42.9 & 49.9 & 0.0009 \\
Cooperia curticei & - & 9.1 & 4.8 & & \\
Over all & 90.0 & $\mathbf{1 0 0 . 0}$ & 95.2 & & \\
\hline
\end{tabular}

\section{Postmortem worm burden count results}

Mean worm burden of pathogenic nematode species such as Haemonchus contortus, Bunostomum trigonocephalum, Teladorsagia spp. and Trichostrongylus axei was found to be significantly high during wet season of the year $(\mathrm{P}<0.05)$ as shown on table 6 below.

Table 6: Mean worm count for nematode species of sheep and by season of the year.

\begin{tabular}{lcccc}
\hline & \multicolumn{2}{c}{ Mean worm burden(S.E) } & & \\
\cline { 2 - 3 } & Dry $(\mathrm{N}=10)$ & Wet(N=11) & P & T \\
\hline Trichostrongylus axei & $50.0(34.2)$ & $181 . .8(122.0)$ & 0.018 & 6.69 \\
T. colubriformis & $1280.0(415.7)$ & $2636.4(657.4)$ & 0.467 & 0.551 \\
T. falculatus & $380.0(268.6)$ & 0.0 & 0.002 & 13.1 \\
T. longispicularis & $80.0(80.0)$ & 0.0 & 0.029 & 5.60 \\
Haemonchus contortus & $251.0(106.5)$ & $1510.0(468.4)$ & 0.001 & 14.4 \\
Teladorsagia spp. & $30.0(30.0)$ & $163.6(22.3)$ & 0.037 & 5.00 \\
Oesophagostomum columbianum & $20.3(10.2)$ & $27.6(9.3)$ & 0.997 & 0.00 \\
Bunostomum trigonocephalum & $2.5(2.5)$ & $9.7(6.5)$ & 0.027 & 5.74 \\
Trichuris ovis & $6.9(2.0)$ & $2.1(1.4)$ & 0.257 & 1.37 \\
Cuperia curticei & 0.00 & $22.7(22.7)$ & 0.048 & 4.47 \\
\hline
\end{tabular}

Mean total nematode burden and mean worm count of Haemonchus contortus was significantly high in sheep than goat $(\mathrm{P}<0.05)$ as shown on table 7 below. 
Table 7: Mean nematode species count of sheep and goats in the study site during the study period.

\begin{tabular}{lcccc}
\hline & \multicolumn{2}{c}{ Mean worm burden(S.E) } & & \\
\cline { 2 - 3 } & Ovine $(\mathbf{N}=14)$ & Caprine(N=7) & p & T \\
\hline Trichostrongylus axei & $85.7(71.7)$ & $185.7(142.1)$ & 0.277 & 1.25 \\
T. colubriformis & $2071.4(592.7)$ & $1828.6(450.8)$ & 0.302 & 1.12 \\
T. falculatus & 0.0 & $542.9(374.1)$ & 0.000 & 31.9 \\
T. longispicularis & $57.1(57.1)$ & 0.0 & 0.147 & 2.287 \\
Haemonchus contortus & $1185.0(405.0)$ & $361.4(102.6)$ & 0.005 & 10.17 \\
Teladorsagia spp. & $150.0(97.1)$ & 0.0 & 0.033 & 5.25 \\
Oesophagostomum columbianum & $13.4(7.1)$ & $45.7(11.3)$ & 0.575 & 0.325 \\
Bunostomum trigonocephalum & $7.6(5.2)$ & $3.6(3.6)$ & 0.228 & 1.553 \\
Trichuris ovis & $3.6(1.3)$ & $6.0(3.0)$ & 0.031 & 5.462 \\
Cooperia curticei & 0.0 & $35.7(35.7)$ & 0.002 & 12.16 \\
Over all & $3573.9(856.0)$ & $301.0(387.5)$ & 0.006 & 9.55 \\
\hline
\end{tabular}

Mean worm burden of Haemonchus contortus was significantly high in older ages than young flock in the study sites during the study period $(\mathrm{P}<0.05)$ as indicated on the table 8 below.

Table 8: Mean nematode species count by the age groups of sheep and goats during the study period.

\begin{tabular}{|c|c|c|c|c|}
\hline & \multicolumn{2}{|c|}{ Mean worm burden(S.E) } & \multirow[b]{2}{*}{$\mathbf{p}$} & \multirow[b]{2}{*}{$\mathbf{T}$} \\
\hline & $6 \mathrm{~m}-1 \mathrm{yr}(\mathrm{N}=13)$ & $>1 \mathrm{yr}(\mathrm{N}=8)$ & & \\
\hline Trichostrongylus axei & $169.2(103.40)$ & $37.5(37.5)$ & 0.05 & 4.29 \\
\hline T. colubriformis & $1923.1(568.5)$ & $2100.0(629.1)$ & 0.81 & 0.05 \\
\hline T. falculatus & 0.0 & $475.0(339.9)$ & 0.00 & 23.0 \\
\hline T. longispicularis & $61.5(61.5)$ & 0.0 & 0.17 & 2.87 \\
\hline Haemonchus contortus & $623.0(256.9)$ & $1377.5(602.8)$ & 0.05 & 4.31 \\
\hline Teladorsagia spp. & $161.5(104.1)$ & 0.0 & 0.02 & 6.55 \\
\hline Oesophagostomum columbianum & $10.5(4.8)$ & $46.2(12.9)$ & 0.04 & 4.97 \\
\hline Bunostomum trigonocephalum & $4.2(4.2)$ & $9.6(6.8)$ & 0.25 & 1.41 \\
\hline Trichuris ovis & $4.6(1.4)$ & $4.00(2.7)$ & 0.24 & 1.43 \\
\hline Cuperia curticei & $19.2(19.2)$ & 0.0 & 0.12 & 2.87 \\
\hline Over all & $2977.1(693.2)$ & $4049.9(1039.4)$ & 0.81 & 0.06 \\
\hline
\end{tabular}


The mean count of Haemonchus contortus was significantly high in poor conditioned sheep and goats than good conditioned sheep and goats $(\mathrm{P}<0.05)$ as indicated on the table 9 below.

Table 9: Mean nematode species count by the body condition of slaughtered sheep and goats.

\begin{tabular}{lccccc}
\hline & \multicolumn{2}{c}{ Mean worm burden(S.E) } & & \\
\cline { 2 - 3 } & Good $(\mathbf{N}=11)$ & Poor(N=10) & & p & T \\
\hline Trichostrongylus axei & $181.8(121.9)$ & $50.0(34.1)$ & & 0.01 & 6.69 \\
T. colubriformis & $1909.1(673.6)$ & $2080.0(501.9)$ & 0.79 & 0.06 \\
T. falculatus & 0.0 & $380.0(268.6)$ & 0.002 & 13.1 \\
T. longispicularis & 0.0 & $80.0(80.0)$ & & 0.02 & 5.59 \\
Haemonchus contortus & $498.2(187.1)$ & $1364.0(534.2)$ & 0.002 & 13.04 \\
Teladorsagia spp. & $1909.1(121.7)$ & 0.00 & & 0.005 & 9.82 \\
Qesophagostomum columbianum & $15.4(6.6)$ & $33.8(11.9)$ & & 0.09 & 3.18 \\
Bunostomum trigonocephalum & $5.0(5.0)$ & $7.7(5.5)$ & & 0.56 & 0.33 \\
Trichuris ovis & $4.1(1.5)$ & $4.7(2.2)$ & & 0.39 & 0.77 \\
Cuperia curticei & $22.7(22.7)$ & 0.00 & 0.05 & 4.46 \\
Over all & $2827.2(783.9)$ & $4000.2(858.6)$ & 0.89 & 0.02 \\
\hline
\end{tabular}

The overall worm count results indicated that higher percentage $(70.0 \%)$ of slaughtered sheep and goats had moderate level of nematode counts while $30.0 \%$ of them were with light infection (Table 10 ).

Table 10. The Intensity of Nematode count from sheep and goats examined by postmortem examination during the study period.

\begin{tabular}{lccccccc}
\hline Intensity (Level of infection) & \multicolumn{6}{c}{ Animal species } \\
\cline { 2 - 8 } & \multicolumn{2}{c}{ Sheep } & \multicolumn{2}{c}{ Goats } & \multicolumn{2}{c}{ Total } \\
\cline { 2 - 8 } & No & $\%$ & No & $\%$ & No & $\%$ \\
\cline { 2 - 8 } Light $(<2000$ nematodes) & 4 & 30.8 & 2 & 28.6 & 6 & 30.0 \\
Moderate (2000-10000 nematodes) & 9 & 69.2 & 5 & 71.4 & 14 & 70.0 \\
Severe $(>10,000)$ & - & - & - & - & - & - \\
\hline
\end{tabular}




\section{Results of Coprological examination}

\section{Coprological prevalence}

Coprological examination of 236 fecal samples collected during dry season and 250 fecal samples collected during wet season of the study period revealed higher prevalence of helminth infection during wet season of the year, which coincides with the higher prevalence of nematode prevalence during the wet season of the year. The trematode and cestode infection were found to be higher during dry season of the year than during wet season as shown in figure 3 below.

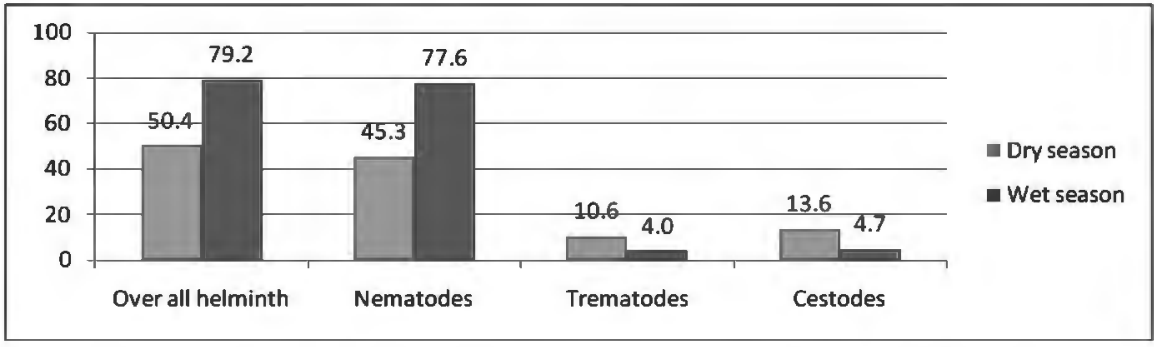

Figure 2. Seasonal point prevalence of helminth infection from fecal samples collected from small ruminants during the study period.

\section{Fecal egg count results}

Sex, species, age and agro-ecological difference didn't cause significant variation on the fecal egg count from sampled animals during the study period (Table 11). 
Table 11: Mean EPG count of sampled animals during the study period by species, sex, age \& agroecological zone.

\begin{tabular}{cccc}
\hline Varable & No & Mean ( S.E) & P \& F value \\
\hline Sex: Male & 118 & $149.2(21.6)$ & $\mathrm{P}=0.78$ \\
Female & 368 & $153.1(11.1)$ & $\mathrm{F}=0.078$ \\
Species: Ovine & 339 & $153.4(11.9)$ & $\mathrm{P}=0.8$ \\
Caprine & 147 & $149.3(17.7)$ & $\mathrm{F}=0.055$ \\
Age (years): $<1$ & 167 & $163.0(17.0)$ & \\
$1-2$ & 128 & $148.1(19.8)$ & $\mathrm{P}=0.9$ \\
$>2$ & 190 & $145.6(15.6)$ & $\mathrm{F}=0.005$ \\
AEZ: High land & 199 & $147.8(15.2)$ & \\
Mid land & 141 & $166.5(18.3)$ & $\mathrm{P}=0.8$ \\
Low land & 146 & $144.3(18.5)$ & $\mathrm{F}=0.065$ \\
\hline
\end{tabular}

The overall mean fecal worm egg count of wet season was found to be significantly higher than that of dry season $(\mathrm{P}<0.05)$. Difference in agro-ecology, age and species of host have shown significant difference in mean worm egg count during dry season but not during wet season (Table 12).

Table 12: Mean EPG count by Agro-ecology, Age, sex, season of year and by species of animals

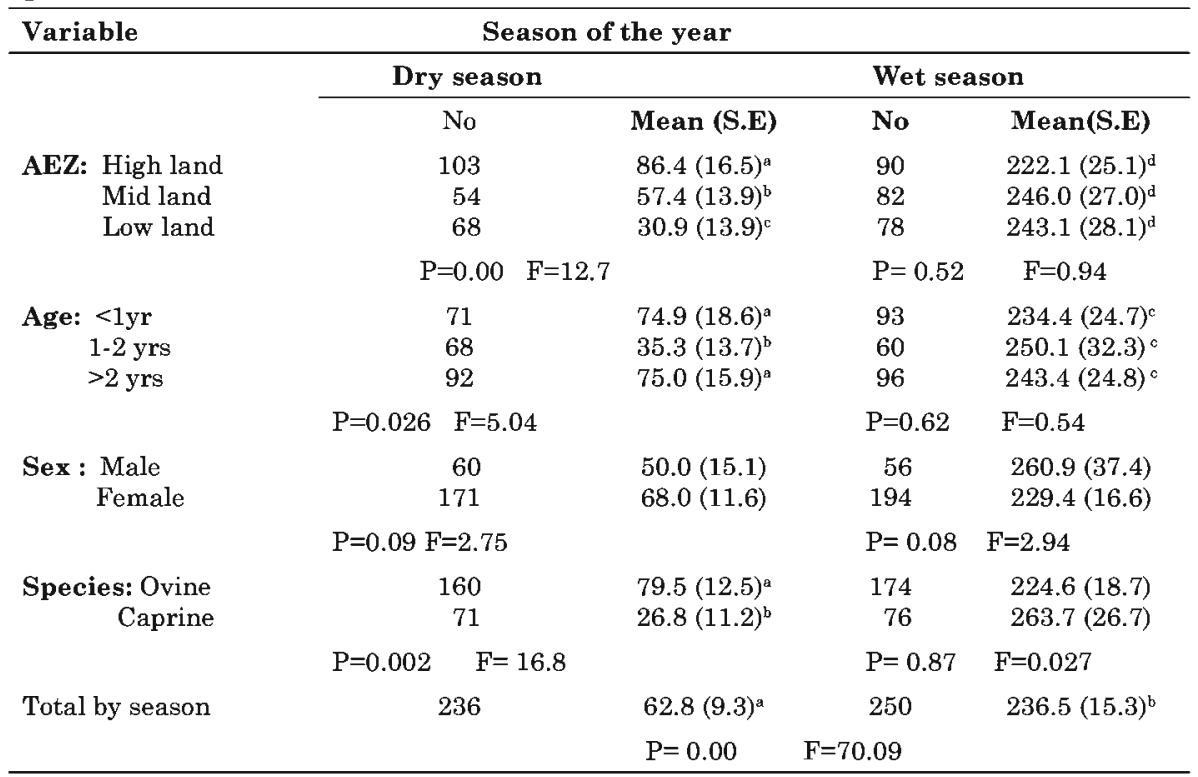


The intensity of nematode infection from 236 fecal samples examined during dry season and 250 fecal samples examined during wet season, has revealed marked seasonal variation. The findings also shown that $74.6 \%$ of the examined animals during the dry season and $27.6 \%$ in wet season harbored 0 or $<50$ eggs per gram of feces. The percentage of light and moderate infection rates were found to be higher in wet season than dry season and based on fecal worm egg count, heavy level of infection was only observed in wet season of the study period (Figure3).

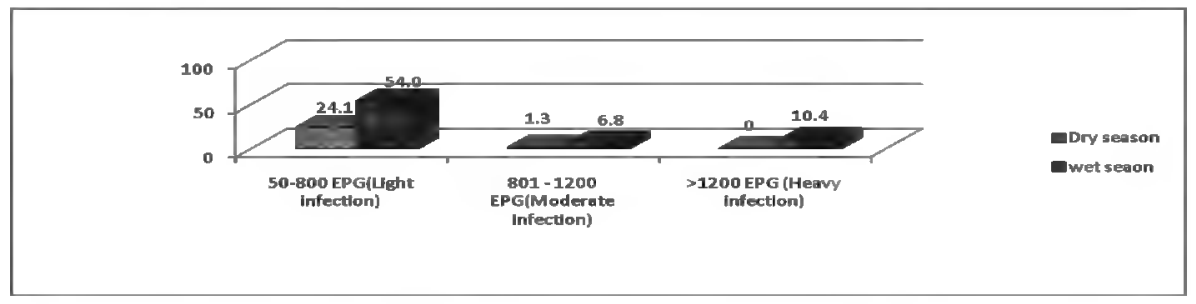

Figure 3. Figure indicating the percentage of intensity of nematode infection based on fecal worm egg count.

\section{Discussion}

\section{Postmortem examination findings}

The present study by postmortem examination of 21 sheep and goats has revealed the overall high prevalence of nematodes (95.2\%), moderate prevalence of cestodes (33.3\%) and low prevalence of trematode infection (4.8\%). This high prevalence of nematodes of this study agrees with the previous work of Amenu and Abebe (2007), who reported the prevalence of 100, $98.3 \& 98.3$ percent prevalence at Bonke, Mirab Abaya and Sodo Zurya woredas of Southern Ethiopia respectively. Again this high nematode prevalence agrees with previous findings in different corners of Ethiopia (Tesfalem Tekie 1989 (in Bale), Genene Regassa, 1994 (in Wollo)) but higher than the reports of Jacquiet et al., 1992 (in Mouritania); Abdalla and Elmalik, 1997 (in Sudan); Achenef Melaku 1997 (in North Shoa) and Haileleul Tesema, 2002 (in Wolaita).

The significantly higher helminth prevalence observed during wet season of the year than dry season of this study might be related to the higher humidity and lower temperature of the wet season, which is favorable for nematode larval development and survival, and existence and abundance of intermediate 
hosts for trematodes and cestodes during wet season of the year (Jacquiet et al., 1995; Dunn, 1978; Soulsby, 1986; Troncy, 1989; Anene et al., 1994; Urquhart et al., 1996; Nwosu et al.,1996; Tembely et al., 1997; Radostitis et al., 2000).

The present study revealed ten different nematode species with different prevalence and the nematode species (Haemonchus contortus, T. colubriformis and $O$. columbianium) which are highly pathogenic to small ruminants found to exist at high prevalence $(85.7 \%, 76.2 \%$ and $52.4 \%)$ respectively. This finding agrees with the finding of Amenu Asha and Abebe Wosene, 2007 and Sisay Menkir, 2007. These pathogenic nematode species are responsible for the losses of production and productivity of small ruminants due to their effect on blood loss, malfunction of small intestine and other related pathological consequences (Kelly, 1973; Troncy, 1989; Soulsby, 1986; Urquhart et al., 1996; Fox, 1997; Bowman, 1999).

The prevalence of different pathogenic nematode species in this study varies depending up on the agroecology. There was higher prevalence of $H$. contortus in lowland, than high and mid lands; and high prevalence of T. colubriformis in high land agro ecology than the other two agroecologies. This variation of nematode prevalence on agroecological basis might be related to the parasites adaptation to different temperature and humidity ranges, that Haemonchus species prefers hot humid environment and Trichostrongylus species prefers cool humid environment for their larval development and survival (Troncy, 1989; Urquhart et al., 1996; Bowman, 1999).

The prevalence and worm burden of $T$. colubriformis, $H$. contortus, $O$. columbianum, and $B$. trigonocephalum was significantly higher during wet season of the year while the prevalence of $T$. ovis was significantly high during dry period of the year. This finding might be related to the favorable climatic condition of wet season for the development and survival of free living larvae of the above four stated nematode species (Troncy, 1989; Urquhart et al., 1996; Fritsche, 1993; Bowman, 1999), while the second stage larvae of $T$. ovis remain unhatched with in the resistant thick egg shell and gets access to be ingested by the host during dry season when the animals are forced to graze at the level of ground due to shortage of grass (Troncy, 1989).

The mean worm burden in sheep was significantly higher than that of goats

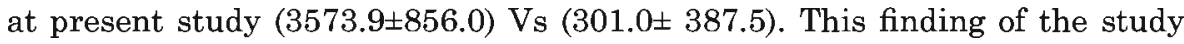
might be related to the availability of excess grazing and browsing materials at the low land areas of the study site where goats were raised, so that goats 
can graze and browse well above the level of ground that the nematode larvae could not reach in large number to be ingested by goats than the over grazed high and mid land portion of the study site where sheep were forced to graze near the ground and usually around the fecal pellets which harbor large number of third stage larvae of nematodes.

Poor conditioned sheep and goats of the study site harbored significantly higher number of pathogenic blood sucking abomasal parasite $H$. contortus than good conditioned sheep and goats. This might be related to the degree of pathogenicity of $H$. contortus than other nematodes in causing weight loss and death of hosts (Troncy, 1989; Urquhart et al., 1996; Bowman, 1999).

\section{Coprological examination findings}

The findings of significantly higher $(\mathrm{p}<0.05)$ seasonal prevalence of nematode infection in corpological examination of this study (77.6\%) during wet season than dry season (45.3\%) was positively related to significantly higher $(\mathrm{P}<0.05)$ prevalence and worm burden of most pathogenic and proliferative nematode species such as $H$. contortus, Teladorsagia spp, Trichostrongylus axei and $T$. colubriformis, whose free living larvae could reach infective third stage larvae and therefore get better chance to infect grazing sheep and goats successfully during wet season than the harsh dry season that kills free living larvae before it reaches infective third stage larvae due to high temperature and low moisture (Troncy, 1989; Frifsche et al, 1993; Hansen and Perry, 1994; Craig, 1998).

The mean EPG count during two seasons of the year was significantly different $(\mathrm{P}<0.05)$, in that during wet season there was higher count than the dry season. This might be related to the favorable climatic condition of the wet season for parasite larvae development and survival and so that there is high level of larval infestation and establishment in the digestive tract of hosts; these infected larvae mature and lay egg with in short period of time and the eggs appear in feces (Troncy, 1989; Fritsche et al, 1993; Hansen and Perry, 1994; Craig, 1998). The favorable climatic condition (temperature and moisture) of wet season equally favored for larval development and survival in all AEZ, thus variation by AEZ, sex, host species and age of host doesn't cause significant difference in EPG count, while in the dry season, the environmental condition in low land is unfavorable due to desiccation and most free living larvae dies out and the number of third stage larvae infecting the host becomes few 
so that few worms reach maturity to lay eggs than the wet and cooler region of the highland.

The EPG count of ovine was significantly higher during dry season than those of goats, this might be related to the agroecological variation since most goats were sampled from lowland areas and most sheep were sampled from high and mid land because of their proportion in the study area.

\section{Conclusion}

The epidemiological study on GIT Helminthosis of small ruminants carried out at two woredas of Dawuro Zone (Loma \& Tocha) during March to August 2012 has shown $100 \%$ of overall prevalence for helminth parasites. The study has shown high prevalence of Nematode infection (95.2\%), moderate prevalence of Cestode infection (33.3\%) and low prevalence of Trematode infection (4.8\%) during the study period. Post mortem examination of 21 sheep and goats during dry and wet seasons of the year resulted in the identification of ten nematode species, of which the pathogenic nematodes such as $H$. contortus, $T$. colubriformis and $O$. columbianum existed at higher prevalence. Even though, this study was carried out for short period of time (6 months), and may not be possible to conclude the overall picture of GIT helminthosis of sheep and goats in Dawuro zone; the finding of higher prevalence with higher worm burden, needs great attention to control the problem of GIT nemotodiosis in the area. Therefore, based on the facts and findings of the present study, the following points are recommended:1) further study covering all the months of the year (seasons), which are important from epidemiological point of view should be carried out to design the strategic treatment regimen 2) the anthelmintics efficacy against GIT nematodiosis of sheep and goats at Dawuro zone should be assessed in order to choose the most effective anthelmintics in the area for the treatment of sheep and goat helminthes in the area.

\section{Acknowledgements}

The authors would like to acknowledge Wolaita Sodo University for funding the study and providing overall support. Our gratitude extends to the Sodo regional veterinary laboratory and Loma Wereda Agricultural office for their technical and material support.

References

Ethiop. Vet. eI., 2015, $19(1), 63-82$ 
Abdalla Ahmed, E. A.and Elmalik, K. H., 1997. Prevalence of nematodes parasitism in desert sheep brought to Khartoum state. Sudan J. of Vet. Sci. and Ani. Husbandr,. $36,2,44-49$.

Abebe, W.and Esayas, G., 2001. Survey of Ovine and Caprine gastrointestinal helminthosis in Eastern part of Ethiopia during the dry season of the year. Revue de Med. Vet., 152 5,379-384.

Achenef, M., 1997. Observation on Ovine Gastrointestinal Nematodiosis and Coenuroses in sheep populations in Debre Berhan. DVM thesis, Faculty of Veterinary Medicine, Addis Ababa University.

Adane, H.and Girma, A., 2008. Economic Significance of sheep and Goats. In: Sheep and goat production hand book for Ethiopia. Chapter 1.

Amenu, A. And Abebe, W.,2007. Gastrointestinal tract nematodiosis of small ruminants in three different agroecological zones in Southern Ethiopia. Ethiop.Vet. J., 11, 1.

Anene, B. M., Onyekwodiri, E. O., Chime, A. B. and Anika, S. M., 1994. Gastrointestinal tract parasites in sheep and goats of southern Nigeria. Small Ruminant Research, 13, 187-192.

Bowman, D. D. 1999. Georgis' Parasitology for Veterinarians. $7^{\text {th }}$ edn., USA: W.B.Saunders Company, pp.144-220.

Craig, T. M., 1998. Epidemiology of internal Parasites. IN: Small Ruminants for mixed animal practitioner. Western Veterinary Conference, Las-Vegas, Feb.1-5/1998, WBC-986, pp.29-37.

Dawuro Zone Bureau of Agriculture 2012. Annual report on livestock production and its problems of 2004 E.C.

Desalegn, L., 1999. The Epidemiology of Strongyle infection in Small Ruminants under warm tropical environment. Ethiop. Vet. J. Proceedings of the $13^{\text {th }}$ conference, pp.50-58.

Devendra, C. and Mcleory, G. B., 1982. Goat and sheep production in the Tropics. Singapore: ELBS with Longman. pp.1-7.

Dunn, A.M., 1978. Veterinary Helminthology $2^{\text {nd }}$ edn. London: William Heinemann Medical Books Ltd., pp.19-35, 173-191.

Esayas, G., 1999. A study on gastrointestinal helminthes, with special emphasis on Haemonchus species, of small ruminants in Arid and Semi-arid zones of eastern Ethiopia. DVM thesis, Faculty of Veterinary Medicine, Addis Ababa University.

Etana, D., 2002. Epidemiology of gastrointestinal tract helminthiasis of rift vally goats under traditional husbandry system in Adamitulu district, Ethiopia. SINET Ethiop. J. Sci., 25, 1, 35-44. 
Fox M.T. 1997. Pathophysiology of infection with gastrointestinal nematodes in domestic ruminants: Recent developments. Vet. Parasitol., 72, 3 \& 4, $285-308$.

Fritsche, T.,Kaufmann and J., Pfister, K. (1993): Parasite spectrum and seasonal epidemiology of gastrointestinal nematodes of small ruminants in The Gambia. Vet. Parasitol., 49, 3 \& 4, 271-283.

Gatenby, R.M. 1991.Sheep: In the Tropical Agriculturalist. Macmillan, TCTA, pp. 6-10.

Genene, R. 1994. A study on the prevalence of Ovine Gastrointestinal tract helminthes in and around Kombolcha. DVM Thesis, Faculty of Veterinary Medicine, Addis Ababa University.

Haileleul, N., 2002. Study on prevalence of Gastrointestinal Helminthes of small ruminants in and around Wolayta Soddo. DVM thesis, Faculty of Veterinary Medicine, Addis Ababa University.

Hendrix, C.M., 1998. Diagnostic Veterinary Parasitology. $2^{\text {nd }}$ edn. USA: Mosby, Inc., pp.108-116, 136.

Ibrahim, H., 1998. Small ruminant production techniques. ILRAD, Manual No.3, ILRI, Nairobi, Kenya. pp. 1-36.

Jacquiet, P., Cabaret, J., Colas, F., Dia, M.L., Cheikh, D. and Thiam, A., 1992. Helminths of sheep and goats in desert areas of south-west Mauritania. Vet. Research Com.,16, 437-444.

Jacquiet, P., Colas,F., Cabaret, J., Dia, M.L., Cheikh, D. and Thiam, A.,1995. Dry areas: an example of seasonal evolution of helminth infection of sheep and goats in southern Mourtania. Vet. Parasitol., 56, 137-148.

Hansen, J and Perry, B., 1994. The epidemiology, Diagnosis and control of helminth parasites of ruminants. Kenya, A handbook, ILRAD.

Kaufmann, J., 1996. Parasitic Infections of Domestic Animals: A Diagnostic Manual. Germany: Birkauser Verlag, pp. 152-166.

Kelly, J.D., 1973. Immunity and epidemiology of helminthiasis in grazing animals. New Zealand Vet. J.; 21, 9, 183-191.

MAF F., 1977. Manual of Veterinary Parasitological Laboratory Techniques. Ministry of Agriculture, Fisheries and Food agricultural development and advisory service. London: Technical bulletin. No.18, pp.1-55.

Mike, S., 1996. Goats: In the Tropical Agriculturalist. Macmillan, TCTA, pp.79-83.

Nwosu, C.O., Ogunrinade, A. F. and Fagbemi, B. O., 1996. Prevalence and seasonal changes in the gastrointestinal helminths of Nigerian goats. J. Helminthol., 70, 4, 329-333. 
Over, H. J., Jansen, J. andVon Olm, P. W., 1992.Distribution and Impact of Helminth Diseases of Livestock in Developing Countries. FAO Animal Production and Health Paper 96. FAO (Food and Agriculture Organization of the United Nations), Rome, Italy, pp. 221.

Radostits, O. M., Gay, C.C., Blood, D.C. and Hinchcliff, K. W., 2000. Veterinary Medicine. A textbook of diseases of cattle, sheep, pigs, goats, and horses. $9^{\text {th }}$ edn. USA, W.B. Sounders Company Ltd, pp. 1339-1352.

Sissay, M.M., 2007. Helminth Parasites of Sheep and Goats in Eastern Ethiopia. Doctoral Thesis, Swedish University of Agricultural Sciences, Uppsala.

Soulsby, E.J.L., 1982. Helminths, Arthropods and Protozoa of Domestic animals. $7^{\text {thedn. }}$. London: Bailliere, Tindall and Cassell. pp. 136-228, 334.

SPSS, 2007. SPSS for windows, Version 16.0. SPSS inc., 1989-2007.

Tembely, S., Lahlou, K. A., Rege, G.E.O., Sovani, S., Diedhiou and M. L., Baker, R. L. 1997. The epidemiology of nematode infections in sheep in cool tropical environment. Vet. Parasitol., 70, 1-3, 129-141.

Tesfalem, T. 1989. Prevalence of GI helminthes of small ruminants in Bale. DVM Thesis, Faculty of Veterinary Medicine, Addis Ababa University.

Thrusfield, M., 1995. Veterinary Epidemiology, UK, Blackwell Science, $2^{\text {nd }}$ edn. pp.17897.

Toma, B., Dufour, B., Sqnna, M., Bennet, J.J, Moutou, F., Louza, A. and Ellis, P., 1996. Applied Veterinary epidemiology and the control of disease in populations. Translated from the French edition. pp.1-162.

Troncy, P.M., 1989 Helminthes of Livestock and Poultry in tropical Africa. In: Manual of Tropical Veterinary Parasitology. UK: CAB International, TCTA, pp.11-15, 2454.

Kocho, T. and Geta E., 2011. Agro-ecologic mapping of livestock system in smallholder crop-livestock mixed farming of Wolaita and Dawuro districts, Southern Ethiopia. Livestock Research for Rural Development. 23, 3.

Urquhart, G. M., Armour, J., Duncan, J. L., Dunn, A.M.and Jenning, F. W. ,1996. Veterinary Parasitology, UK: Black well Science, $2^{\text {nd }}$ edn. pp. 10-99, 257-271. 